\title{
PRODUÇÃO DE $\alpha$-AMILASES POR Rhizomucor miehei E Syncephalastrum racemosum EM DIFERENTES CONDIÇÕES FERMENTATIVAS
}

\begin{abstract}
ARAÚJO, Aline Silva ${ }^{1}$ MARTINS, Eduardo da Silva ${ }^{1}$

RESUMO: Amilases são enzimas com diversas aplicações industriais, com destaque para a $\alpha$-amilase, utilizada na indústria alimentícia, têxtil e sucroalcooleira. Este trabalho teve por objetivo avaliar a influência da temperatura de incubação, umidade inicial do substrato e adição de bagaço de cana-de-açúcar sobre a produção de $\alpha$-amilase dos fungos Rhizomucor miehei e Syncephalastrum racemosum em farelo de trigo, e caracterizar as enzimas. Foram avaliados os valores de umidade de $60 \%, 70 \%$ e $80 \%$, temperatura de incubação do fungo a $45^{\circ} \mathrm{C}, 50^{\circ} \mathrm{C}$ e $55^{\circ} \mathrm{C}$ para $R$. miehei e $25^{\circ} \mathrm{C}, 30^{\circ} \mathrm{C}$ e $35^{\circ} \mathrm{C}$ para $S$. racemosum e adição de bagaço de cana ao farelo de trigo a $10 \%, 30 \%$ e $40 \%$. Para $R$. miehei, a maior atividade ocorreu em umidade de $60 \%$ e $70 \%$, com o fungo incubado a $45^{\circ} \mathrm{C}$. Para $S$. racemosum, em umidade de $60 \%$ e $70 \%$, com o fungo incubado a $25^{\circ} \mathrm{C}$. Concentrações de bagaço de cana em $30 \%$ e $40 \%$ diminuiram a atividade das enzimas. $\mathrm{O}$ pH ótimo das enzimas foi entre 4,0 e 5,5 para os dois fungos. A temperatura ótima foi $75^{\circ} \mathrm{C}(R$. miehei $)$ e $70^{\circ} \mathrm{C}($ S. racemosum $)$. A enzima produzida por $R$. miehei apresentou maior termoestabilidade, enquanto a de $S$. racemosum mostrou estabilidade em uma maior faixa de pH. A produção de $\alpha$ amilase pelos fungos avaliados foi influenciada por todos os fatores avaliados, reforçando a importância do estudo de parâmetros fermentativos na produção de $\alpha$-amilases fúngicas. A enzima obtida do fungo $R$. miehei tem potencial para aplicação em processos industriais que requerem enzimas termofílicas e termoestáveis.
\end{abstract}

Palavras-chave: enzimas, fungos, fermentação.

SUMMARY: Amylases are enzymes with various industrial applications, especially the $\alpha$-amylase, used in the food, textile and sugar industry. This study aimed to evaluate the influence of incubation temperature, substrate moisture and sugarcane bagasse addition on the production of $\alpha$-amylase by the thermophilic fungus Rhizomucor miehei and the mesophilic fungus Syncephalastrum racemosum in wheat bran, and characterize the enzymes. Moisture values for the $60 \%, 70 \%$ and $80 \%$, temperatures of $45^{\circ} \mathrm{C}, 50^{\circ} \mathrm{C}$ and $55^{\circ} \mathrm{C}\left(\right.$ R. miehei) and $25^{\circ} \mathrm{C}, 30^{\circ} \mathrm{C}$ and $35^{\circ} \mathrm{C}$ (S. racemosum) and sugarcane bagasse concentrations of $10 \%, 30 \%$ and $40 \%$ were evaluated. Regarding to $R$. miehei, the highest activity occurred in moisture of $60 \%$ and $70 \%$, with the fungus incubated at $45^{\circ} \mathrm{C}$. Regarding to S. racemosum, in moisture of $60 \% 70 \%$, with the fungus incubated at $25^{\circ} \mathrm{C}$. Concentrations of sugarcane bagasse at $30 \%$ and $40 \%$ decreased the $\alpha$-amylases activity. The optimum $\mathrm{pH}$ was between 4.0 and 5.5 for the two fungi. The optimal temperature was $75^{\circ} \mathrm{C}\left(R\right.$. miehei) and $70^{\circ} \mathrm{C}(\mathrm{S}$. racemosum). The enzyme from $R$. miehei showed a higher thermostability, whereas that produced by $R$. miehei showed a greater range of $\mathrm{pH}$ stability. The $\alpha$-amylase production by the evaluated fungi was influenced by the initial substrate moisture content, incubation temperature of fungi and addition of sugarcane bagasse to wheat bran, reinforcing the importance of fermentative parameters studies in the fungal $\alpha$-amylases production. The enzyme from $R$. miehei has potential for application in industrial processes that require thermophilic and thermostable enzymes.

Keywords: Enzymes. Fungus. Fermentation.

\section{INTRODUÇÃO}

O Brasil, por ser um país de grande atividade agrícola, é um dos que mais produzem subprodutos agroindustriais, tais como bagaço e palha de cana-de-açúcar, bagaço de laranja, farelo de soja, farelo de trigo, palha de milho (SANTOS et al., 2018). A tendência atual é de aproveitar estes materiais, obtendo

\footnotetext{
${ }^{1}$ Universidade do Estado de Minas Gerais
} 
produtos com alto valor agregado, como as enzimas (MENEZES; SILVA; DURRANT, 2009; REINEHR et al., 2016). A fermentação em estado sólido é empregada na produção de diversos tipos de enzimas com aplicação industrial. Este processo, além de geralmente ser mais eficiente que a fermentação submersa na produção enzimática, permite a utilização de diferentes resíduos agroindustriais como substrato para o crescimento microbiano, os quais muitas vezes são descartados e/ou usados para finalidades que pouco agrega valor aos mesmos (SAXENA; SINGH, 2011). Por sua ampla disponibilidade e por representar uma fonte alternativa de baixo valor comercial, o aproveitamento destes materiais pode contribuir para a redução do custo operacional da produção enzimática, além de minimizar possíveis impactos ambientais decorrentes do seu descarte inadequado (LEITE et al., 2007). Diversos subprodutos têm sido avaliados como substratos para produção de enzimas microbianas, como bagaço de cana-de-açúcar, bagaço de laranja, farelos de milho, arroz etc, sendo que o farelo de trigo tem sido destaque. Na maioria dos estudos, o farelo de trigo tem sido o substrato de escolha para a indução de amilases por ser um material rico em proteínas, carboidratos e minerais, que promovem um adequado suprimento de macro e micronutrientes para o crescimento microbiano (SINGHANIA et al., 2011; STROPARO et al., 2012,).

As amilases constituem um dos mais importantes grupos de enzimas com aplicações industriais. Estas enzimas são responsáveis pela degradação da molécula de amido, e podem ser aplicadas nas indústrias de alimentos, têxtil, farmacêutica, papel e celulose, sucroalcooleira, dentre outras (FERNANDES, 2007; GOPINATH et al., 2017), sendo responsáveis por cerca de $25 \%$ da produção mundial de enzimas, ocupando o segundo lugar, logo após as proteases (SOUZA; MAGALHÃES, 2010).

Devido às vantagens que a produção enzimática microbiana oferece, como a facilidade de produção e o amplo espectro de aplicações, a amilase microbiana tem sido a preferida em relação à outras fontes para produção (SUNDARRAM; MURTHY, 2014). Dentre as amilases, a mais importante é a $\alpha$ amilase, que desempenha um papel fundamental na conversão do amido em produtos de baixo peso molecular, os quais podem ser utilizados por outras enzimas do mesmo grupo (SOUZA; MAGALHÃES, 2010).

No processo de fermentação em estado sólido (FES), há vários fatores importantes que afetam a produção de enzimas microbianas, dentre eles a linhagem microbiana e o substrato. Além disso, a seleção de parâmetros fermentativos é fundamental para o bom rendimento da fermentação (PANDEY et al., 2000). Em trabalhos prévios (BERNARDES et al., 2014; FREITAS; MARTINS; FERREIRA, 2014), a produção de $\alpha$-amilase pelos fungos Rhizomucor miehei (termofílico) e Syncephalastrum racemosum (mesofílico) foi avaliada, estabelecendo condições fermentativas como tipo de substrato, tempo de cultivo, pH inicial do substrato e suplementação com fontes de nitrogênio. Assim, o objetivo do presente trabalho foi avaliar a influência de outros fatores fermentativos, como umidade inicial do substrato, temperatura de incubação dos fungos e adição de bagaço de cana-de-açúcar ao substrato farelo de trigo sobre a produção da enzima $\alpha$-amilase pelas duas linhagens fúngicas, além de caracterizar as enzimas nas melhores condições de produção obtidas.

\section{MATERIAL E MÉTODO}

\section{Micro-organismos}

Foram utilizadas duas linhagens fúngicas, uma termofílica (Rhizomисor miehei) e uma mesofílica (Syncephalastrum racemosum), disponíveis no Laboratório de Microbiologia da UEMG de Frutal/MG, avaliadas como boas produtoras de $\alpha$-amilases termofílicas em estudos preliminares. As linhagens foram identificadas pela Micoteca da Universidade Federal de Pernambuco (UFPE). 


\section{Meio de cultivo para inóculo e substratos para a fermentação e obtenção do extrato enzimático}

Os fungos usados foram cultivados em Erlenmeyers de $500 \mathrm{~mL}$, contendo meio Sabouraud com amido a $1 \%$. Os mesmos foram incubados a $28^{\circ} \mathrm{C}$ (mesofílico) e $45^{\circ} \mathrm{C}$ (termofílico), até apresentarem bom crescimento.

Nos frascos contendo cada fungo, foram adicionados $100 \mathrm{~mL}$ de solução salina esterilizada, composta por sulfato de amônia $\left(\mathrm{NH}_{4}\right)_{2} \mathrm{SO}_{4}$ a $0,1 \%$ (para o fungo termofílico) e $100 \mathrm{~mL}$ de água destilada (para o fungo mesofílico) (BERNARDES et al., 2014; FREITAS; MARTINS; FERREIRA, 2014). A superfície do meio foi suavemente raspada com alça de inoculação esterilizada, obtendo-se assim uma suspensão micelial. Foram também preparados e esterilizados $\left(121^{\circ} \mathrm{C} / 30 \mathrm{~min}\right)$ meios de cultivo em Erlenmeyers de $250 \mathrm{~mL}$, contendo $5 \mathrm{~g}$ de farelo de trigo.

Inicialmente, os meios de cultivo para fermentação foram inoculados com a suspensão micelial, de modo que a umidade do farelo de trigo fique em torno de $70 \%$, e incubados em estufa a $28^{\circ} \mathrm{C}$ (mesofílico) e $45^{\circ} \mathrm{C}$ (termofílico), durante 3 e 2 dias, respectivamente (esses valores de tempo de cultivo também foram determinados em trabalhos prévios (BERNARDES et al., 2014; FREITAS; MARTINS; FERREIRA, 2014), com a substituição de outros substratos avaliados para o fungo $R$. miehei pelo farelo trigo, o qual em testes posteriores demonstrou ser mais eficiente para indução da produção da enzima. Para a obtenção do extrato enzimático, $40 \mathrm{~mL}$ de água destilada foram adicionados em cada Erlenmeyer. Estes foram agitados a $100 \mathrm{rpm}$ em "shaker" durante 30 minutos e posteriormente o seu conteúdo foi filtrado e centrifugado a $3000 \mathrm{rpm}$ por 20 minutos. O sobrenadante foi o extrato enzimático bruto a ser analisado.

\section{Avaliação de diferentes condições fermentativas para a produção enzimática}

Foram estudadas as seguintes temperaturas de cultivo: $25^{\circ} \mathrm{C}, 30^{\circ} \mathrm{C}$ e $35^{\circ} \mathrm{C}$ para o fungo mesofílico e $40^{\circ} \mathrm{C}, 45^{\circ} \mathrm{C}$ e $50^{\circ} \mathrm{C}$ para o fungo termofílico. Com relação à umidade inicial do farelo de trigo, foram avaliados os valores de 60\%,70\% e $80 \%$, para os fungos Rhizomucor miehei e Syncephalastrum racemosum.

Também foi avaliada a produção da enzima com e sem adição de bagaço de cana-de-açúcar ao farelo de trigo. $\mathrm{O}$ bagaço de cana foi testado como suporte para diminuir a compactação do farelo de trigo. Foi lavado com água corrente, seco a $80^{\circ} \mathrm{C}$ até peso constante, moído e peneirado usando peneira para seleção de partículas de $0,5 \mathrm{~mm}$. Este foi misturado ao farelo de trigo, também secos em estufa a $60^{\circ} \mathrm{C}$ e moídos, nas proporções de 10\%/90\%, 30\%/70\% e 40\%/60\%. Os materiais, após misturados e homogeneizados, foram esterilizados em autoclave a $120^{\circ} \mathrm{C}$ por 30 minutos.

Os experimentos foram feitos em três repetições. Os dados foram submetidos à análise de variância (ANOVA) e quando significativo realizou-se a comparação de médias pelo teste de Tukey a 5\% de probabilidade. Foi analisada a influência dos seguintes fatores sobre a produção enzimática: temperatura de incubação dos fungos, umidade inicial do substrato e adição de diferentes concentrações de bagaço de cana-de-açúcar.

\section{Caracterização dos extratos enzimáticos}

Nas melhores condições fermentativas determinadas, os extratos enzimáticos foram caracterizados em relação ao pH e temperatura ótimos para atuação amilolítica, visando otimizar as condições físicoquímicas de maior atuação na quebra do amido. Também foi avaliada a estabilidade das enzimas em relação ao pH e à temperatura, para que se possa avaliar sua resistência frente à variações destes dois fatores. 
O comportamento da atividade das enzimas em função do $\mathrm{pH}$ foi estudado incubando a solução enzimática e substrato em tampões $0,2 \mathrm{~mol} \mathrm{~L}^{-1}$ acetato $(\mathrm{pH} 3,5$ a 5,5), Citrato $(\mathrm{pH}$ 6,0 a 7,0) e Tris ( $\mathrm{pH} 7,5$ a 9,0), sendo dosada a atividade inicialmente a $60^{\circ} \mathrm{C}$. O efeito da temperatura sobre a atividade enzimática foi avaliado incubando-se a mistura de reação em temperaturas de $40^{\circ} \mathrm{C}$ a $80^{\circ} \mathrm{C}$ (com variação de $5^{\circ} \mathrm{C}$ ), e a atividade foi medida no $\mathrm{pH}$ determinado como ótimo.

A estabilidade em diferentes valores de $\mathrm{pH}$ foi avaliada incubando-as em tampões $0,2 \mathrm{~mol} \mathrm{~L}^{-1}$ acetato (pH 3,5 a 5,5), Citrato ( $\mathrm{pH} 6,0$ a 7,0) e Tris ( $\mathrm{pH} 7,5$ a 9,0), em ausência de substrato, a $25^{\circ} \mathrm{C}$, por 24 horas. Após esse período, foram tomadas amostras para ensaiar a atividade residual, nas condições de pH e temperatura determinados como ótimos para a atividade das enzimas.

Com relação à estabilidade à temperatura, a enzima foi mantida por uma hora, em ausência de substrato, em temperaturas de $10^{\circ} \mathrm{C}$ a $80^{\circ} \mathrm{C}$. Após esse período, foram tomadas amostras para ensaiar a atividade enzimática, nas condições de $\mathrm{pH}$ e temperatura ótimos.

\section{Medida da atividade de $\alpha$-amilase (reação dextrinizante)}

A atividade de $\alpha$-amilase foi determinada medindo-se a diminuição da capacidade de ligação entre o amido e o iodo de uma solução de amido tratada com uma solução enzimática bruta seguindo o método descrito por Fuwa (1954). Das soluções enzimáticas obtidas a partir da fermentação semi-sólida, foi utilizado $0,9 \mathrm{~mL}$ de solução de amido solúvel a $0,3 \%$ (p/v) em tampão acetato $0,25 \mathrm{M}, \mathrm{pH}$ 5,0 e $0,1 \mathrm{~mL}$ da solução enzimática bruta convenientemente diluída. Após incubação a $60^{\circ} \mathrm{C}$, por 10 minutos, a reação foi paralisada pela adição de 4,0 $\mathrm{mL}$ de solução de $\mathrm{HCl}$ 0,2 $\mathrm{M}$, sendo em seguida adicionado $0,5 \mathrm{~mL}$ de reativo de Iodo (KI 0,30\% + $\mathrm{I}_{2}$ 0,03\%). Após homogeneização, a mistura de reação foi diluída com $10 \mathrm{~mL}$ de água destilada.

O controle foi preparado conforme o processo descrito, porém em duas etapas: o controle do substrato (amido) foi preparado substituindo-se a enzima pelo volume equivalente em água destilada e o controle da enzima, substituindo-se a solução de amido pelo volume equivalente de tampão acetato. Em espectrofotômetro, a absorbância foi determinada a $600 \mathrm{~nm}$ contra um branco constituído de água destilada. Uma unidade de enzima (U) é definida como a quantidade de enzima requerida para hidrolisar $10 \mathrm{mg}$ de amido em 10 minutos nas condições de ensaio.

\section{RESULTADO E DISCUSSÃO}

\section{Influência dos fatores umidade inicial do substrato e temperatura de incubação dos fungos}

Pode-se observar que a umidade influenciou a produção de $\alpha$-amilase pelos dois fungos avaliados, sendo tanto para $R$. miehei quanto para $S$. racemosum os valores de umidade de $60 \%$ e $70 \%$ proporcionaram maior produção da enzima, com valores estatisticamente diferentes aos encontrados quando a umidade foi de $80 \%$ (Figura 1).

Com relação ao fator temperatura de incubação dos fungos, pode-se observar que este também foi um fator que afetou a produção de $\alpha$-amilase pelos dois fungos avaliados, sendo que para $R$. miehei, que é um fungo termofílico, a melhor temperatura dentre as avaliadas foi de $45^{\circ} \mathrm{C}$, com valor estatisticamente diferentes aos demais. Já para S. racemosum, a atividade foi maior quando o fungo foi incubado a $25^{\circ} \mathrm{C}$, também com diferença estatística significativa em relação às atividades enzimáticas nas outras temperaturas (Figura 1). 
Foi observado também que a adição de bagaço de cana-de-açúcar ao farelo de trigo diminuiu a atividade das enzimas dos dois fungos (Figura 1)

Figura 1: Influência dos fatores umidade inicial do substrato, temperatura de incubação dos fungos e adição de bagaço de cana-de-açúcar ao farelo de trigo, sobre a produção das $\alpha$-amilases. - $\square$ - $R$. miehei; - $\square-$ S. racemosum. Letras diferentes indicam diferença estatística pelo teste Tukey $(\mathrm{P}<0,05)$. Letras iguais não diferem entre si significativamente, para cada fungo
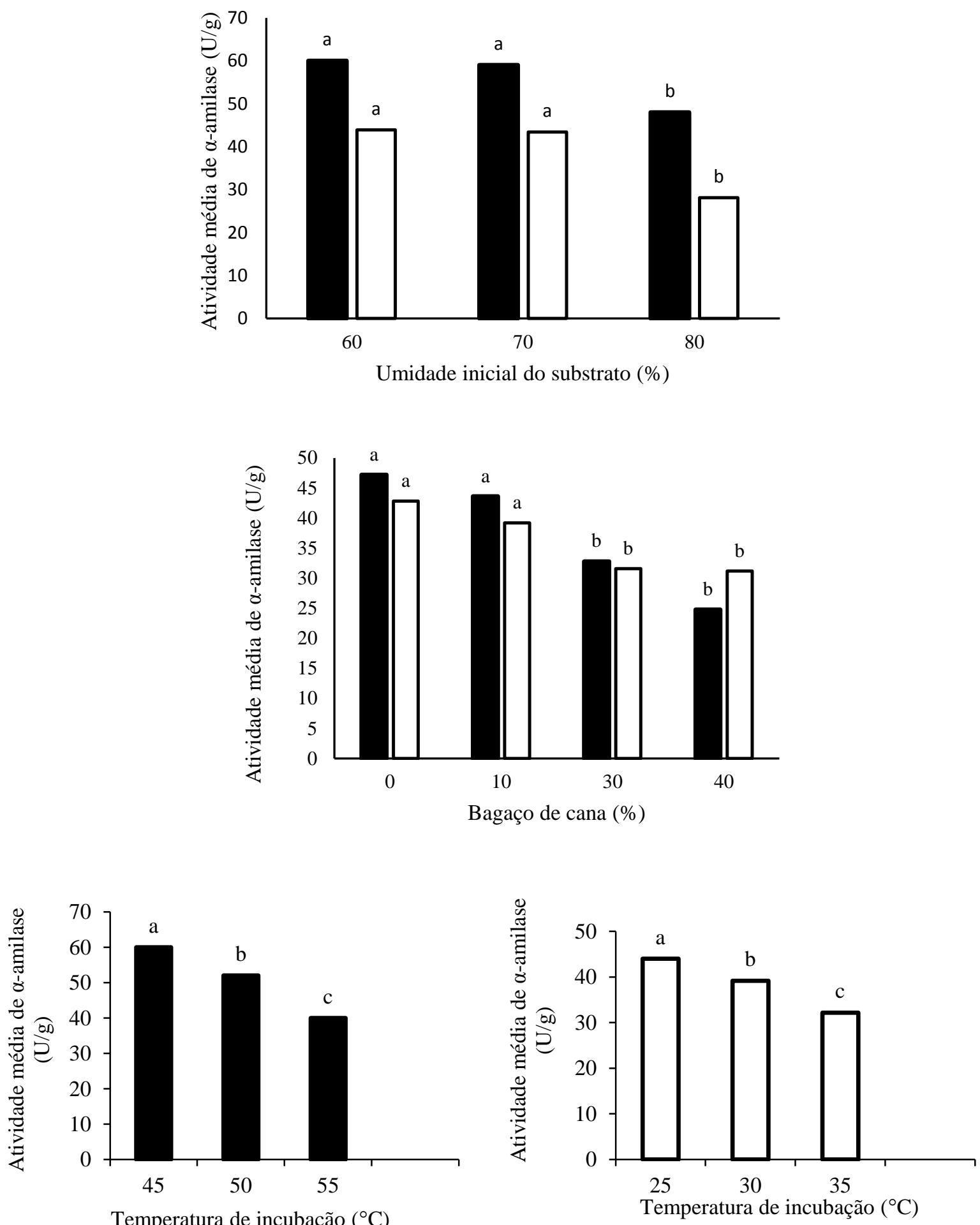

Nucleus,v.15,n.2,out.2018 
Com relação à temperatura de incubação, a baixa condutividade térmica dos resíduos agroindustriais utilizados em processos de fermentação em estado sólido pode dificultar a dissipação do calor metabólico gerado pelo crescimento microbiano (PANDEY et al., 2003). Assim, a análise da temperatura de cultivo é essencial para delinear um bioprocesso para produzir enzimas (SANTOS et al., 2016).

Com relação ao teor de umidade inicial do substrato, este é outro parâmetro fundamental de ser analisado na fermentação em estado sólido. De forma geral, teores de umidade inferiores a $60 \%$ e superiores a $80 \%$ são menos favoráveis ao crescimento fúngico e à produção de celulases em fermentação em estado sólido. Quando o teor de umidade é inferior ao nível requerido, a solubilidade dos nutrientes é limitada e dificulta a absorção efetiva destes pelos fungos. Por outro lado, quando é elevado, as partículas de substrato são cercadas por uma espessa camada de água, tendendo a ficarem juntas e limitando as trocas gasosas. Além disso, em valores elevados de umidade, o risco de contaminação por outros microrganismos é maior (YOON et al., 2014; SANTOS et al., 2016).

Em relação à adição de bagaço de cana-de-açúcar ao farelo de trigo, a diminuição da atividade das amilases quando em concentrações mais elevadas de bagaço sugere menor indução na sua produção, uma vez que o farelo de trigo possui em torno de $24,9 \%$ de amido, enquanto que no bagaço de cana praticamente não há amido (DORNEZ et al., 2006).

\section{Caracterização físico-química da enzima produzida}

Efeito do $\mathrm{pH}$ sobre a atividade das enzimas

Observou-se que as enzimas produzidas pelos dois fungos têm característica de melhor atuação em valores de $\mathrm{pH}$ entre 4,0 e 5,5, com valores bem próximos entre si nessa faixa de $\mathrm{pH}$ (Figura 2A). Em valores de $\mathrm{pH}$ acima de 6,0, a atividade decresceu. Assim, os dados indicam que o fungo produz uma amilase que pode ser aplicada em processos que requerem valor de $\mathrm{pH}$ mais ácidos, especialmente entre 4,0 e 5,5 .

Este valor de $\mathrm{pH}$ ótimo é inferior aos valores encontrados para o fungo Penicillium rugulosum, que foi de 7,0 (TIWARI; RADHAV; FATIMA, 2007), e para o fungo Thermomyces lanuginosus, que produziu uma amilase de $\mathrm{pH}$ ótimo 6,0 (KUNAMNENI; PERMAUL; SING, 2005). Com relação à estabilidade ao $\mathrm{pH}$, observou-se que a enzima produzida por $R$. miehei apresentou maior estabilidade em valores de $\mathrm{pH}$ entre 5,0 e 6,0, enquanto que a enzima obtida do fungo $S$. racemosum apresentou uma maior faixa de estabilidade ao $\mathrm{pH}$, principalmente na faixa entre 4,5 e 6,5 (Figura 2B). 
Figura 2: Efeito do $\mathrm{pH}$ sobre a atividade das $\alpha$-amilases. - - $R$. miehei; - $\square-$ S. racemosum. $\quad$ A- pH ótimo das enzimas; $\mathrm{B}$-Estabilidade das $\alpha$-amilases à variações de $\mathrm{pH}$, quando expostas por 24 horas, na ausência de substrato, a diferentes valores de $\mathrm{pH}$.
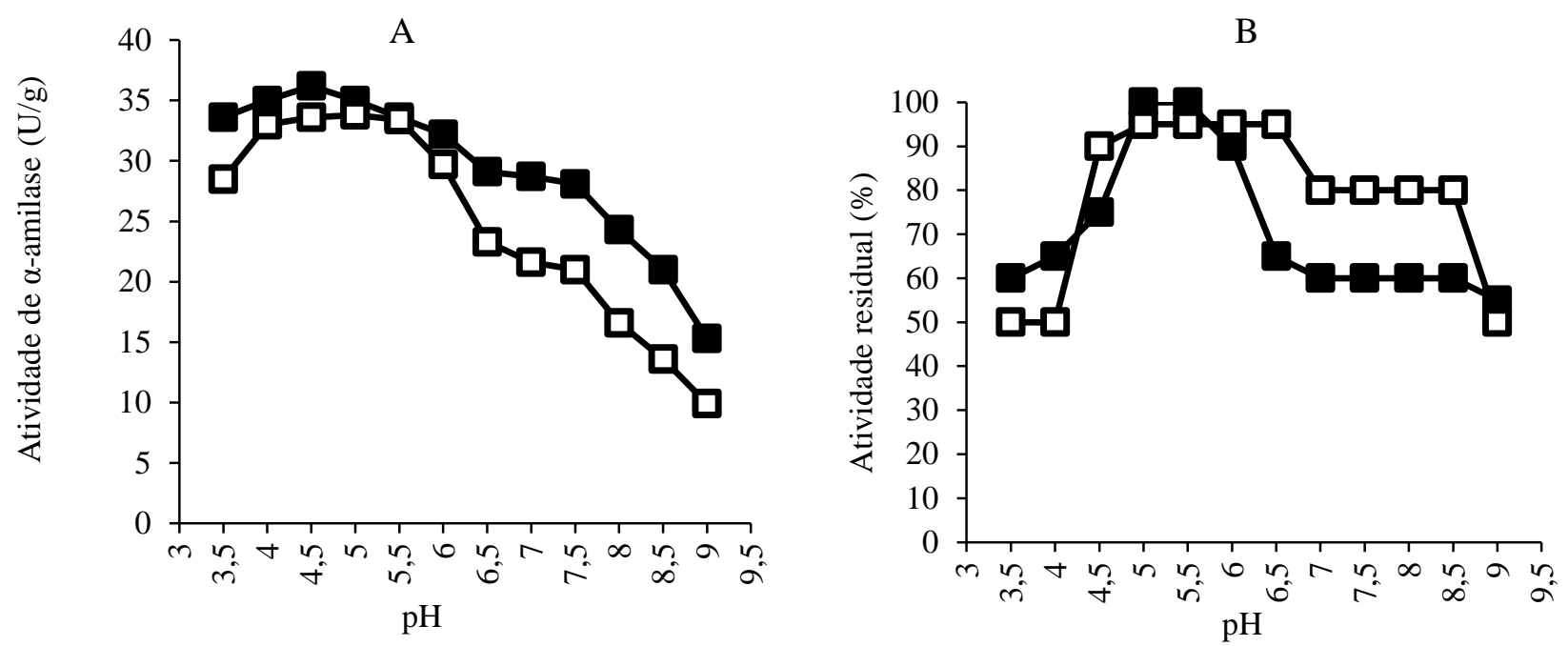

\section{Efeito da temperatura sobre a atividade das enzimas}

A temperatura ótima da amilase produzida pelo fungo $R$. miehei foi de $75^{\circ} \mathrm{C}$, enquanto que a do fungo S. racemosum foi de $70^{\circ} \mathrm{C}$ (Figura 3A). Estes valores são elevados em relação à maioria dos fungos filamentosos produtores de amilase relatados na literatura, que produzem amilases com atividade máxima em temperaturas inferiores a $60^{\circ} \mathrm{C}$, tais como Aspergillus niger, Penicillium camemberti, Penicillium olsonii, (HUSSAIN et al., 2013), Thermomyces lanuginosus (KUNAMNENI; PERMAUL; SING, 2005) e Penicillium rugulosum (TIWARI; RADHAV; FATIMA, 2007).

Com relação à termoestabilidade, a enzima produzida por $R$. miehei apresentou mais de $90 \%$ de estabilidade, quando incubada por 1 hora, até a temperatura de $65^{\circ} \mathrm{C}$, com acentuado decréscimo acima deste valor. Já a enzima produzida por $S$. racemosum apresentou estabilidade superior a $90 \%$ até $50^{\circ} \mathrm{C}$, cerca de $80 \%$ a $55^{\circ} \mathrm{C}$ e decresceu bruscamente a $60^{\circ} \mathrm{C}$ (Figura 3B). Assim, os dados indicam maior termoestabilidade da enzima produzida pelo fungo termofílico, em relação ao mesofílico. 
Figura 3: Efeito da temperatura sobre a atividade das $\alpha$-amilases. - - $R$. miehei; - $\square-$ S. racemosum. A -Temperatura ótima; B - Termoestabilidade das $\alpha$-amilases, quando expostas por 1 hora em diferentes temperaturas.

A

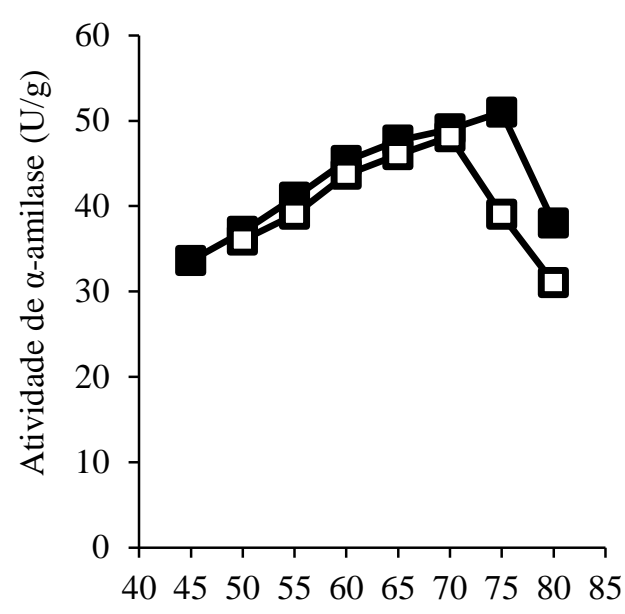

Temperatura $\left({ }^{\circ} \mathrm{C}\right)$
B

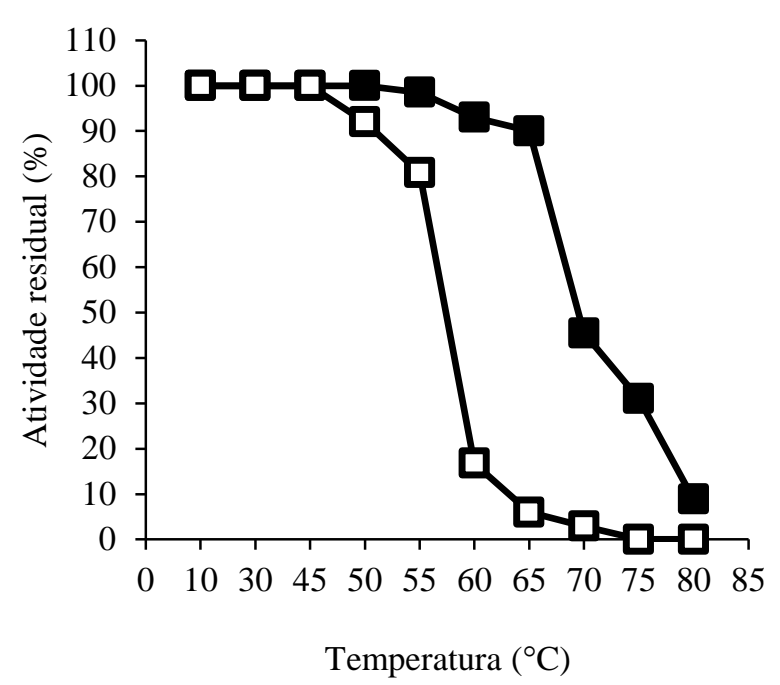

A atividade em altas temperaturas, bem como a termoestabilidade das enzimas até temperaturas entre $50^{\circ} \mathrm{C}$ e $55^{\circ} \mathrm{C}$ aumenta seu uso em aplicações industriais que exigem temperaturas elevadas, bem como favorece sua aplicação em processos que exigem a inativação completa da enzima com o aumento da temperatura no processo, como na indústria de panificação (CORONADO et al., 2000).

As condições de $\mathrm{pH}$ e temperatura para as fases de liquefação e sacarificação do amido em processos industriais são definidas de modo a evitar subprodutos indesejáveis e, principalmente, levando em consideração condições ótimas de atividade e de estabilidade das enzimas. A etapa crítica do processo é a de sacarificação, a qual usa enzimas de mesófilos e, portanto, com menor termoestabilidade, requerendo o resfriamento do material e controle para que a temperatura não ultrapasse $60{ }^{\circ} \mathrm{C}$. Enzimas sacarificantes mais termoestáveis são desejáveis nesse processo, pois evitariam o passo de resfriamento e, consequentemente, levariam à redução de custos (GOMES et al., 2007).

Dessa forma, a enzima do fungo $R$. miehei estudada no presente trabalho tem potencial para aplicação em processos industriais que requerem enzimas que atuam em altas temperaturas e apresentem boa termoestabilidade.

\section{CONCLUSÃO}

Todos os parâmetros fermentativos analisados afetaram a produção de $\alpha$-amilase pelos fungos $R$. miehei e $S$. racemosum em farelo de trigo. A atividade das enzimas foi maior quando os fungos foram cultivados em farelo de trigo sem adição de bagaço de cana-de-açúcar e com adição de 10\%, com umidade inicial de $60 \%$ e $70 \%$. A adição de $30 \%$ e $40 \%$ de bagaço de cana-de-açúcar ao farelo de trigo diminuiu a atividade das amilases. A maior atividade das amilases obtidas de $R$. miehei e $S$. racemosum ocorreu quando os fungos foram incubados a $45^{\circ} \mathrm{C}$ e $25^{\circ} \mathrm{C}$, respectivamente, demonstrando ser este um fator fundamental na expressão das enzimas pelos fungos. A enzima produzida por R. miehei apresentou 
atividade em elevadas temperaturas, bem como boa termoestabilidade, tendo potencial para aplicação em processos industriais que requerem amilases termofílicas e termoestáveis.

\section{AGRADECIMENTO}

À Fundação de Amparo à Pesquisa de Minas Gerais, pela Bolsa de Iniciação concedida no programa PIBIC/UEMG/FAPEMIG.

\section{REFERÊNCIAS}

BERNARDES, A.et al. Utilização de subprodutos agroindustriais para produção de $\alpha$-amilase por Rhizoтисо miehei. Revista Brasileira de Tecnologia Agroindustrial, v. 8, n. 2, p. 1439-1451, 2014.

CORONADO, M.et al. Production and biochemical characterization of an $\alpha$-amylase from the moderate halophile Halomonas meridiana. FEMS Microbiology Letters, v. 183, p. 67-71, 2000.

DORNEZ, E.et al. Insight into the distribution of arabinoxylans, endoxylanases, and endoxylanase inhibitors in industrial wheat roller mill streams. Journal of Agricultural and Food Chemistry, v. 54, p. 8521-8529, 2006.

FERNANDES, L. P. et al. Produção de Amilases pelo fungo Macrophomina phaseolina. Revista Eletrônica de Farmácia, v. 4, n. 1, p., 43-51, 2007.

FUWA, H. A. A new method for microdetermination of amylase activity by the use of amilose as the substrate. Journal of Biochemistry, v. 41, n. 5, p. 583-603, 1954.

FREITAS, L. S.; MARTINS, E. S.; FERREIRA, O. E. Produção e caracterização parcial de $\alpha$-amilase de Syncephalastrum racemosum. Revista Brasileira de Biociências, v. 12, n. 4, p. 226-232, 2014.

GOMES, E.et al. Enzimas termoestáveis: fontes, produção e aplicação industrial. Química Nova, v. 30, n. 1, p. 136-145, 2007.

GOPINATH, S. C. B.et al. Biotechnological processes in microbial amylase production. BioMed Research International, v. 2017, n. 2017, p. 1-9, 2017.

KUNAMNENI, A.; PERMAUL,K.; SINGH, S. Amylase production in solid state fermentationby the thermophilic fungus Thermomyces lanuginosus. Journal of Bioscience and Bioengineering, v. 100, n. 2, p. 168-171, 2005.

LEITE, R. S. R.et al. Production of cellulolytic and hemicellulolytic enzymes from Aureobasidium pullulans on solid state fermentation. Applied Biochemistry and Biotechnology, v.136, p.251 - 258, 2007.

MENEZES, C. R., SILVA, I. S.; DURRANT, L. R. Bagaço de cana: fonte para produção de enzimas ligninocelulolíticas. Estudos Tecnológicos, v. 5, n. 1, p. 68-78, 2009.

PANDEY, A. Solid-state fermentation. Biochemical Engineering Journal, v. 13, p. 81-84, 2003.

PANDEY, A.; SOCCOL, C. R.; MITCHELL, D. New developments in solid state fermentation: Ibioprocesses and products. Process Biochemistry, v. 35, n. 10, p. 1153-1169, 2000. 
REINEHR, C. O.et al. Produção de lipases com atividade de hidrólise por Aspergillus utilizando subprodutos agroindustriais, óleo de soja e glicerol. Revista Ciências Exatas e Naturais, v. 18, n. 1, p. 97-115, 2016.

SANTOS, F. R. S.et al. Production and characterization of $\beta$-glucosidase from Gongronella butleri by solid-state fermentation. African Journal of Biotechnology, v. 15, n. 16, p. 633-641, 2016.

SANTOS, P. S.et al. Fermentação em estado sólido em resíduos agroindustriais para a produção de enzimas: uma revisão sistemática. The Journal of Engineering and Exact Sciences, v. 4, 2018.

SAXENA, R.; SINGH, R. Amylase production by solid-state fermentation of agro-industrial wastes using Bacillus sp. Brazilian Journal of Microbiology, v. 42, n. 4, p. 1334-1342, 2011.

SINGHANIA, R. R.et al. Properties of a major $\beta$-glucosidase-BGL1 from Aspergillus niger NII-08121 expressed differentially in response to carbon sources. Process Biochemistry, v. 46, n. 7, p. 1521-1524, 2011.

SOUZA, P.M.; MAGALHÃES, P.O. Application of microbial $\alpha$-amylase in industry: a review. Brazilian Journal of Microbiology, v. 41, n. 4, p. 850-861, 2010.

SOUZA, T.C. DE et al. Leaf plasticity in successive selection cycles of 'Saracura' maize in response to periodic soil flooding. Pesquisa Agropecuária Brasileira, v.45, p.16-24, 2010.

STROPARO, E. C.et al. Seleção de fungos filamentosos e de resíduos agroindustriais para a produção de enzimas de interesse biotecnológico. Semina: Ciências Agrárias, v. 33, n. 6, p. 2267-2278, 2012.

SUNDARRAM, A.; MURTHY, T. P. K. $\alpha$-amylase production and applications: a review. Journal of Applied \& Environmental Microbiology, v. 2, n.4, p. 166-175, 2014.

TIWARI, K. L.; JADHAV, S. K.; FATIMA, A. Culture condition for the productionof thermostable $\alpha$-amylase by Penicillium rugulosum. Global Journal of Biotechnology \& Biochemistry, v. 2, n. 1, p. 21-24, 2007.

YOON, L. W.et al. Fungal solid-state fermentation and various methods of enhancement in cellulase production. Biomass and Bioenergy, v. 76, p. 319-338, 2014. 